\title{
O PROPÓSITO CRÍTICO: ENTREVISTA COM ALLISON JAMES
}

\author{
Flavia Ferreira Pires ${ }^{*}$ \\ Maria Letícia Barros Pedroso Nascimento**
}

RESUMO: Allison James é pesquisadora renomada no campo dos Estudos da Infância, tendo publicado diversos e importantes artigos e livros. Em suas pesquisas, prioriza o olhar sobre a agência das crianças e sua atuação como atores sociais competentes nas diversas instâncias da sociedade. Esta entrevista foi realizada em 2012, parte pessoalmente e parte por correspondência eletrônica, e pretende trazer um pouco do percurso e das ideias da antropóloga para ampliar o contato de pesquisadores brasileiros interessados nos Estudos da Infância. A entrevista está organizada em tópicos e, ao final, apresenta a produção bibliográfica da pesquisadora.

Palavras-chave: Estudos da infância. Pesquisa. Crianças. Interdisciplinaridade.

\section{THE CRITICAL PURPOSE: INTERVIEW WITH ALLISON JAMES}

ABSTRACT: Allison James is a renowned pioneer researcher on Childhood Studies and has published several important journal articles and books. Her work focuses on children as competent social actors and her research explores their experiences in different aspects of social life. The interview was undertaken in 2012, personally and by electronic email, and aims to bring some of the anthropologist's ideas and experiences to enhance the contact of Brazilian researchers with the field of Childhood Studies. The interview is organized into topics and, at the end, her bibliographic production is presented.

Keywords: Childhood Studies. Research. Children. Interdisciplinarity.

\section{Le BUt ESSENTIEL: ENTRETIEN AVEC Allison JameS}

RÉSUME: Allison James est une chercheuse renommée dans le domaine des études de la petite enfance et a publié plusieurs articles importants et des livres. Dans ses recherches, elle souligne le regard sur la notion d'agency des enfants

\footnotetext{
* Universidade Federal da Paraíba, Centro de Ciências Humanas, Letras e Artes, João Pessoa, Paraíba, Brasil. E-mail de contato ffp23279@gmail.com

** Universidade de São Paulo, Faculdade de Educação, São Paulo, São Paulo, Brasil
} 
et de leur rôle en tant qu'acteurs sociaux compétents à différents niveaux de la société. Cette interview a été réalisée en 2012, soit une part en presentielle soit une autre par courrier électronique et vise à apporter un peu du parcours et des idées de l'anthropologue pour agrandir le contact entre les chercheurs brésiliens intéressés aux études de l'enfance. L'entretien est organisé en thèmes et à la fin il présente la production bibliographique de la chercheuse.

Mots-clés: Études sur l'enfance. La recherche. Les enfants. L'interdisciplinarité.

\section{Introdução}

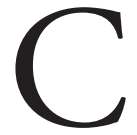

odiretora do Centre for the Study of Childhood and Youth (CSCY), da Universidade de Sheffield, no Reino Unido, e professora da mesma universidade, Allison James é uma pesquisadora renomada no campo dos Estudos da Infância. É coautora de duas publicaçóes 1 "clássicas" do campo, Constructing and reconstructing childhood (1990), com Alan Prout, livro no qual, pela primeira vez, se formula o novo paradigma da infância, e Theorizing Childhood (1998), com Alan Prout e Chris Jenks, que, como revela o título, teoriza uma visão social da infância a partir da apresentação e da análise de diferentes concepçôes de criança, de temas da infância contemporânea e de dualismos conceituais presentes nas Ciências Sociais.

Em 2000 organizou, com Pia Christensen, Research with Children (2000), coletânea de artigos sobre diferentes possibilidades metodológicas para os Estudos da Infância, traduzido para o português em 2005 e publicado em Portugal. Com Adrian James, seu marido, publicou Childhood: Theory, Policy and Practice (2004) e Key Concepts in Childhood Studies (2008), além de organizar European Childhoods: Culture, Politics and Childhood in the European Union (2008).

Tem artigos publicados nos periódicos Childhood, American Anthropologist, Children \& Society, entre outros, e contribuiu com capítulos em vários livros, dos quais destacamos Agency, publicado no Handbook of Childhood Studies (2009) e, recentemente, 'Child-centredness' and 'the child': the cultural politics of nursery schooling in England, em The Modern Child and the Flexible Labour Market: early childhood education and care, de 2011.

Coordenou projetos de pesquisa financiados, dentre os quais Space to Care: Children's Perceptions of Spatial Aspects of Hospitals, com Penny Curtis, estudo sobre as percepçóes infantis sobre o espaço hospitalar e, atualmente, pesquisa as teorias de socialização, tema que será objeto de seu novo livro. 
Em toda a sua vasta e profícua produção acadêmica, Allison James prioriza o olhar sobre a agência das crianças e sua atuação como atores sociais competentes nas diversas instâncias da sociedade. Antropóloga de formação, é muitas vezes lida como socióloga, o que não a aborrece. Antes pelo contrário, o esforço interdisciplinar é uma constante em seus textos e o próprio paradigma dos Estudos da Infância só se sustenta na medida em que é interdisciplinar. Esse diálogo para além das fronteiras disciplinares, no entanto, ultrapassa a academia e envolve os agentes governamentais, os organismos internacionais e as organizaçóes não-governamentais que trabalham com questóes que atingem a infância e a vida das crianças, como o campo dos direitos das crianças.

Embora não reconheça grandes avanços na vida cotidiana das crianças como resultado da sua trajetória acadêmica - como o leitor poderá apreciar durante a entrevista -, Allison James reconhece que os Estudos da Infância foram fundamentais para o estabelecimento de diretrizes e metas que contribuíram para a melhoria da qualidade de vida das crianças globalmente. Como peça fundamental do estabelecimento do paradigma dos Estudos da Infância, a trajetória acadêmica dessa inglesa, simpática e acolhedora, não pode ser negligenciada.

Em julho de 2012, o Centre for the Study of Childhood and Youth (CSCY) comemorou 10 anos de existência promovendo o congresso internacional Celebrating Childhood Diversity, do qual as autoras tiveram a oportunidade de participar e onde esta entrevista foi iniciada. Entretanto, a entrevista, que está sendo disponibilizada ao leitor de língua portuguesa, foi realizada em três momentos distintos: presencialmente durante a conferência em julho de 2012, via correspondência eletrônica em setembro 2012 e presencialmente em novembro de 2012 .

Para nós, trazer um pouco do percurso e das ideias dessa antropóloga pareceu uma boa oportunidade para ampliar o contato de pesquisadores brasileiros interessados nos Estudos da Infância. A entrevista está organizada em tópicos que procuram dar conta dos diversos pontos discutidos, a saber: uma introdução à trajetória pessoal e profissional da pesquisadora; uma apresentação do nascimento e desenvolvimento dos Estudos da Infância; a afirmação da necessidade de manter o propósito crítico nos Estudos da Infância redobrando os esforços teóricos e conceituais; esclarecimentos téoricos e que dizem respeito ao paradigma suscitados principalmente por uma leitura brasileira nesses estudos; o campo de pesquisa sobre infância fora do Reino Unido; e finalmente, conselhos para jovens pesquisadores e perspectivas para o futuro. Para concluir essa introdução, destacamos em sua fala a necessidade de não perder de vista o propósito crítico dos Estudos da Infância, o que quer dizer que devemos nos esforçar para constituir um corpus teórico e conceitual sólido. Para tanto, é necessário manter o diálogo entre as disciplinas. A pergunta que deve ser feita é: como as disciplinas (sociologia, antropologia, educação, psicologia etc.) podem contribuir para melhor entender a vida das crianças? E não o que as crianças têm a contribuir para cada disciplina 
isoladamente. Porém, talvez ainda mais relevante para manter o próposito crítico é indagarmos como as crianças podem contribuir para compreender as grandes questôes societais que estão sendo colocadas atualmente. Significando, em suas palavras, que "precisamos mostrar o valor de trazer a perspectiva das crianças a respeito de outros assuntos além do que diz respeito apenas às crianças”. De um lado, devemos ter em mente a necessidade de um diálogo interdisciplinar que leve à compreensão profunda da infância e, de outro, devemos trabalhar com questóes de pesquisa que dizem respeito à sociedade de modo geral, afinal, "nós já sabemos mais ou menos o acontece no parquinho", mas ainda não sabemos como as crianças influenciam, por exemplo, os destinos políticos ou a economia de um país.

No final da entrevista, apresentamos a produção bibliográfica de Allison James. Buscamos mapear e publicizar os títulos da maioria dos livros, artigos e capítulos publicados, inclusive em coautoria.

Boa leitura!

\section{Sobre Allison James}

\section{Entrevistador 1(E1): Vamos começar pelo início. Você poderia contar um pou- co sobre quem era Allison James quando criança?}

Allison James $(A J)$ : Allison James era uma criança bem solitária. Eu tenho uma irmã que é três anos e meio mais velha que eu, mas eu era uma criança bem quieta e séria. Eu tenho fotos de quando era bem pequena e em todas elas eu não estou sorrindo. Minha mãe dizia que eu costumava brincar muito sozinha. Eu tinha uma amiga com quem eu costumava brincar silenciosamente, sem conversas. Eu costumava brincar de jogos silenciosos. Eu sempre fui muito alta quando criança. Eu sempre achei que as pessoas esperavam mais de mim por causa disso, e eu ainda sou bem alta atualmente. Eu acho que ser uma criança pequena não era muito confortável para mim. Certamente eu não era aquele tipo de menininha bonitinha, não era muito feminina nesse sentido. O que mais posso dizer? Certo, provavelmente até a adolescência eu não era tão sociável e então na adolescência eu me tornei mais sociável, mais interessada em arte e esse tipo de coisa. Eu tive uma boa adolescência.

\section{E1: Você acha que esse tipo de pergunta "quem era você quando criança?" é importante para entender quem você se tornou como pesquisadora?}

AJ: Eu não sei. Essa é realmente uma pergunta difícil. Possivelmente. Eu não tenho uma perspectiva psicanalítica. De fato, eu fugiria desse tipo de perspectiva que diz que o que eu fiz quando criança determina o que eu faço como adulta. 
Eu acho que para mim foram possibilidades e circunstâncias. Talvez se procurasse muito profundamente poderia dizer que por eu ter sido tão quieta e silenciosa quando criança... mas eu não gostaria de fazer esse tipo de afirmação. Penso que você toma decisôes em sua vida e isso abre caminhos específicos para você. Não sou uma daquelas pessoas que gosta de olhar para trás.

E1: Eu me recordo que quando era criança tinha alguns pensamentos e ideias sofisticadas sobre o mundo. Mas as pessoas náo me levavam a sério. Então quando eu me deparei com a perspectiva dos Estudos da Infância eu pensei "isso é algo que eu sempre soube"...

AJ: Não tive esse tipo de experiência. Eu sempre quis escrever, escrevo desde criança. A escrita foi o que me levou à academia. Se não tivesse me tornado uma antropóloga, poderia ter me tornado uma romancista. Escrever é algo que eu sempre fiz, desde muito nova, inicialmente histórias e assim por diante. Minha grande paixão é escrever.

\section{E1: Como você se tornou uma antropóloga?}

AJ: Eu fiz sociologia na Universidade de Durhan na graduação e depois a antropologia me cativou. Inicialmente fiquei encantada pela sociologia e depois tive um orientador, que era especialista em Oriente Médio, chamado David Brooks, que me inspirou com sua abordagem antropológica, afastando-me do caminho de me tornar uma socióloga para me tornar uma antropóloga.

\section{E1: Por que escolbeu fazer a graduaçáo em sociologia?}

AJ: Provavelmente porque não queria fazer alguma coisa que já tinha feito na escola. Queria ir para a universidade, mas não sabia o que fazer. Pensei em alemão e história da arte, pensei em fazer inglês, história e acho que foi minha mãe que disse: "ah, antropologia parece interessante". Então foi absolutamente aleatório, mas penso que foi uma decisão acertada e feliz.

\section{E1: Como você começou a estudar crianças? Você intencionalmente queria observar as crianças ou isso simplesmente aconteceu?}

AJ: Eu estava dividida entre sociologia e antropologia. Estava em meu segundo ano. Estava muito entusiasmada com as ideias marxistas de desenvolvimento e entusiasmada com ideias sobre mudança social. Eu pretendia fazer uma dissertação sobre mudança social na Itália em uma comunidade que conhecia. Mas então fiquei muito doente e deixei a Universidade por um ano. Quando voltei fiz um curso diferente e conheci este professor que se tornou meu orientador. Ele estava lecionando esse curso que mudou radicalmente minhas ideias sobre antropologia... 


\section{E1: Você se lembra que curso era?}

AJ: Ele lecionava Oriente Médio e Religião. Eu fiz dois de seus cursos. Ele não estudava crianças e infância. Eu fazia sociologia ao mesmo tempo e estava muito entusiasmada pela sociologia da educação. Por gostar de literatura e de escrever, tive a ideia de me dedicar à sociologia da literatura como trabalho final da graduação. Meu professor disse que eu estava trabalhando um tópico muito amplo na monografia e por isso deveria reduzir o foco. Ele sugeriu que fizesse algo sobre literatura infantil, e eu fiz. Fiz uma comparação entre a visão de mundo nos livros escritos para crianças na Inglaterra Vitoriana e a comparei com os livros infantis do século XX. Então, enquanto seguia esse caminho, esse antropólogo me disse: "por que você não vai atrás de crianças reais em vez de procurar em livros sobre crianças?”. E foi isso. Sabe, sem planos, nada planejado, sem nenhuma grande decisão ou passos projetados. Eu defini como plano que gostaria de escrever, fiquei muito satisfeita fazendo minha pesquisa e aproveitei as oportunidades na medida em que elas apareceram.

\section{E1: Gostaria de falar um pouco sobre a relaçáo entre antropologia e sociologia e como isso se dá em sua carreira. Algumas vezes você é referida como socióloga. Isso te incomoda ou náo?}

AJ: Eu acho que me movi de uma para outra ao longo da minha carreira. E olhando para trás isso foi muito bom de certa forma. Comecei muito entusiasmada pela sociologia e mudei para a antropologia, voltei para a sociologia e depois novamente para a antropologia. Tem sido um vaivém entre as duas. A antropologia me dá um grande entusiasmo intelectual... Obviamente, minha pesquisa de doutorado e meu primeiro livro são muito mais antropológicos. Então, quando comecei a lecionar - ensinar sociologia, que é o que ainda leciono assim como um pouco de sociologia política - a sociologia me deu um pouco mais de rigor e mais senso de estrutura. Mais noção de coisas muito importantes no que se refere a compreender as crianças e a infância. Tenho tido vontade de voltar para aquele tipo de curiosidade que redireciona as discussóes. Penso que talvez seja mais confortável trabalhar num referencial teórico mais antropológico, com ideias mais filosóficas, mais interdisciplinar... Acho que a antropologia é uma disciplina interdisciplinar, não tem uma substância disciplinar. $\mathrm{Na}$ verdade, não tem, é uma convergência de um conjunto de disciplinas. Eu me voltei para isso. A sociologia me proporciona um rigor e um importante controle dos meus excessos, mas a antropologia me oferece entusiasmo e liberdade. E, para mim, a combinação das duas é muito útil. Tem sido um zig-zag em minha carreira. Porque algumas vezes eu acho que a antropologia pode ser uma disciplina tão ampla e eclética e isso me faz ultrapassar os limites algumas vezes, e a sociologia faz com que me sinta restringida por ela. Colocando-as juntas, tenho o melhor de cada uma. 


\title{
Sobre estudos da infância
}

\begin{abstract}
Entrevistador 2 (E2): Para discutir o 'novo' paradigma da infância (JAMES \& PROUT, 1990, 1997) um pesquisador poderia utilizar a Sociologia da Infância, a Antropologia da Criança, os Estudos Sociais da Infância e os Estudos da Infância. Por que o mesmo campo adimite denominaçóes diferentes? Isso é um sinal de que o campo ainda está em processo de construçáo?
\end{abstract}

AJ: Eu acho que isso depende da perspectiva de cada um e é uma questão à qual me referi em um artigo na [revista] Children's Geographies ${ }^{2}$. Nos anos 80, a infância era um campo novo e muito interdisciplinar e as pessoas vinham de disciplinas diferentes para estudar as crianças e a infância. Entretanto, desde o novo paradigma, e do crescimento de interesse pelas crianças e pela infância, eu posso vislumbrar isso para algumas pessoas. Infância é agora um veículo para estudar as suas disciplinas - que pode ser sociologia, antropologia ou geografia - ao invés de, como no passado, utilizar as suas disciplinas para estudar a infância. Se você fizer este último, então você se abre para perspectivas mais interdisciplinares, e eu usaria, portanto, o termo Estudos da Infância. Em uma perspectiva interdisciplinar você teria, então, a infância como foco principal e utilizaria diferentes disciplinas para compreender a infância. Mas o que está acontecendo é que os Estudos da Infância estão se diversificando e as pessoas estão colando suas disciplinas em primeiro lugar. Dessa forma um geógrafo que poderia estudar infância, ou poderia estudar migração, ou poderia estudar qualquer outra coisa, se preocupa antes com que a infância pode acrescentar à geografia, em vez de em que a geografia pode contribuir para a compreensão da infância. A mim parece que hoje os Estudos da Infância estão se desenvolvendo de duas formas diferentes. E para mim o fundamental é a perspectiva interdisciplinar. Tudo bem, eu sou uma antropóloga, mas trabalho com historiadores, com pessoas da educação, com psicólogos para entender a infância e as crianças porque é nisso que estou interessada. Foi assim que nasceram os primeiros Estudos da Infância, lá atrás nos anos 1970 e 1980, quando tivemos aquelas reunióes em Cambridge quando tivemos diversas disciplinas diferentes se encontrando para discutir crianças e infância. Era isso que era tão empolgante e foi como o novo paradigma cresceu.

\section{E1: Você poderia falar um pouco mais sobre as reunióes em Cambridge?}

AJ: Iniciei minha pesquisa de doutorado fazendo etnografia na Grã-Bretanha com crianças e jovens e publiquei algumas coisas em 1977, se não estou enganada. E então ficou nítido que havia outras pessoas fazendo trabalhos similares. Judith Ennew que estava em Cambridge organizou uma série de reuniōes sobre Etnografia da Infância e reuniu pessoas que, como eu, estavam fazendo suas pesquisas de doutorado ou tinham acabado de finalizá-las. Alan Prout, Jens Qvortrup, Harry 
Hendrick, Jo Boyden estavam todos lá. Todos aqueles que estão no livro Constructing and Reconstructing Childhood estavam lá, reunindo e conversando. Martin Woodhead estava lá. Todos estavam nesses seminários e em outros dois, eu acho. Nós tivemos conversas interdisciplinares maravilhosas e todos compartilhavam esse ponto de vista de pensar as crianças e a infância de uma maneira diferente, em uma perspectiva histórica, psicológica, desenvolvimentista e internacional. Realmente foi muito empolgante.

\section{E1: E isso foi nos anos 1970?}

AJ: Eu acho que no início dos anos 1980. Eu não consigo me lembrar das datas exatas. E em conversas com Alan [Prout] nós decidimos fazer o livro e reunir as pessoas. Foi assim que o livro nasceu, nessas reunióes, nós mencionamos isso no prólogo. Eram tempos emocionantes.

E1: Como as ideias de estudar as crianças como agentes e atores sociais eram contextualizadas nesses encontros nos anos 1980 ou mesmo antes disso por seus colegas e professores?

AJ: Como elas eram compreendidas?

\section{E1: Sim. O que eles pensavam sobre isso?}

AJ: Havia um número de pessoas chegando às mesmas conclusóes ao mesmo tempo, o que eu achei interessante. Havia conversas em vários lugares que buscavam olhar para questóes mais amplas sobre como se entende o mundo. Eu penso que isso diz mais respeito à ascensão da sociologia interpretativa do que a perspectiva antropológica de observação participativa. Havia muitas questóes mais amplas que refletiam sobre o que estávamos pensando. Certamente no meu departamento não havia ninguém mais fazendo isso... Se as pessoas achavam que eu estava um pouco enlouquecida? Eu não sei. Todos tinham suas pesquisas ímpares e essa era a minha. Eu fazia parte de um departamento de antropologia, e considerando que todos estavam fazendo muitas coisas exóticas, tratar as crianças como um tipo de categoria exótica era apenas mais uma coisa exótica a se fazer. As pessoas estavam bem receptivas ao que eu dizia. Uma coisa a respeito de estudar crianças é que todos já foram crianças e têm filhos e, por isso, têm uma opinião sobre crianças de uma forma que eu não tenho uma opinião sobre uma tribo boliviana ou uma comunidade dos Andes. E isso é o mais difícil porque eles dizem: "ah, meus filhos não fazem isso" ou "eu nunca vi isso, portanto você está errada". Havia muito disso no início porque estávamos desafiando suposições muito enraizadas. Pelo menos agora as pessoas estão mais receptivas e sem criar problemas com o que outras pessoas estão interessadas. Havia algo como "as crianças não são uma gracinha?" que eu achava muito problemático no princípio. A ideia de que as crianças dizem 
coisas engraçadas e que nós não levamos isso a sério. Eu me lembro de uma publicação do começo da carreira que tratava de apelidos das crianças ${ }^{3}$ que a imprensa se apossou. Algumas coisas no artigo foram colocadas de forma "fofa", o que me deixou muito, muito brava. Porque eu estava de fato dizendo algo importante sobre relacionamentos sociais das crianças, mas eles trataram isso como se fosse algo fofo e sem seriedade, sem muita importância. Mas, na verdade, o que eu dizia era que apelidos são importantes. Os apelidos eram importantes para as crianças, mas eram tratados como brincadeiras risíveis. Aquilo me deixou muito brava.

\section{E1: Que artigo era esse?}

AJ: Era um artigo numa revista de ciências sociais, mas generalista, New Society. Era para um público mais escolarizado, chamava-se The name of the Game, ou algo assim, não consigo me lembrar, mas acho que foi em 1979. Depois disso foi interpretado de uma maneira muito leviana pelos jornais nacionais, o que me deixou bem brava. Eu tenho me preocupado com a imprensa desde então, me preocupo que interpretem equivocadamente o que quero dizer.

\section{Sobre o próposito crítico dos Estudos da Infância}

\section{E1: Pensando a respeito da história dos Estudos da Infância, o que já foi con- quistado e o que ainda é necessário conquistar?}

AJ: Acho que a visão das crianças é atualmente respeitada de uma maneira que não era anteriormente. Nem sempre, mas é mais respeitada. Isso diz respeito ao Estudos da Infância, mas também a assuntos como a Convenção dos Direitos da Criança. Parte disso é em consequência dos Estudos da Infância, mas eu não sei o quanto disso pode-se dar crédito a esses estudos. Parte disso é em consequência de assuntos mais amplos sobre os direitos da criança. Mas essas duas coisas estão interligadas. Isso é importante. Foi estabelecido um campo de pesquisa a respeito do qual me sinto satisfeita. Eu sempre me lembro de Judith Ennew dizendo que teríamos conquistado alguma coisa quando tivesse uma estante na biblioteca com Estudos da Infância. Hoje há várias estantes contendo Estudos da Infância. Então isso me parece uma conquista. Nós compreendemos mais sobre a vida das crianças, mais sobre as diferenças entre infâncias. Nós imprimimos uma marca importante a respeito do universalismo e do papel determinante da biologia nos cursos ensinados. Esses são grandes desenvolvimentos. $\mathrm{O}$ que eu acho que vai acontecer, ou pode acontecer, é que podemos perder - a não ser que nos Estudos da Infância se comece a lidar com questôes mais teóricas e conceituais - o 
propósito crítico, e pode se tornar novamente um assunto periférico. Portanto, precisamos mostrar o valor de trazer a perspectiva das crianças a respeito de outros assuntos para além do que diz respeito apenas às crianças. Nós não precisamos realmente saber mais sobre o que acontece no parquinho, porque nós já sabemos mais ou menos o acontece no parquinho. Mas precisamos compreender mais, por exemplo, o papel das crianças na economia familiar ou o aspecto político das crianças e da infância. Há coisas muito importantes que precisam ser feitas para mantermos esse propósito crítico.

\section{E1: Você acha que os Estudos da Infância tornaram as vidas das crianças me- lhores?}

AJ: Provavelmente não. Talvez para algumas crianças. Isso depende, é difícil saber se foram os Estudos da Infância ou se foram os direitos das crianças, pois isso tende a ser muito mais. E há ainda os entrecruzamentos de ambas. Eu não estou certa de que qualquer coisa que eu tenha feito tornou a vida das crianças melhores... Talvez pequeninas mudanças, mas nada grande. Mas se contribuiu para uma compreensão diferente das crianças e da infância, então, de uma maneira bem ampla talvez tenha ajudado. Hoje nós respeitamos a ideia de que devemos ouvir o que as crianças têm a dizer muito mais que antes. Então, talvez nesse sentido.

\section{Sobre o paradigma e a teoria}

\section{E1: Qual o papel do conceito de agência nos Estudos da Infância? Pode-se pensar em agência sem pensar em estrutura? Por quê? Como pensar em agência em sociedades náo individualistas como as sociedades tradicionais indígenas, ciganas e quilombolas?}

AJ: Essa é uma grande questão! Agência, muito brevemente, é a habilidade de agir e fazer as coisas acontecerem e nesse sentido era um conceito crucial no início, já que as crianças não eram realmente pensadas como atores sociais. Elas eram apenas objetos, não sujeitos. Atualmente talvez seja mais complicado visto que as discussóes teóricas sobre agência/estrutura se desenvolveram, e é preciso pensar sobre a dialética entre agência e estrutura em termos de análise da agência das crianças - então em sociedades nas quais há ideias menos individualistas de 'agência' talvez seja diferente e diferentemente articulada em relação a individualidade, identidade e assim por diante. Embora no nível mais simples de se pensar agência as crianças nessas sociedades obviamente, as crianças agem e fazem coisas no seu dia a dia. Como essas açóes são interpretadas pelos outros, e o crédito dado às suas ações, é o ponto interessante. 
E1: No que se refere à metodologia, você ainda afirma que a etnografia é o melhor método para pesquisar crianças?

AJ: Não - é um entre muitos, mas como antropóloga eu ainda adoraria fazer mais etnografia. Tempo e dinheiro frequentemente tornam isso irreal agora e o crescimento de abordagens participativas significa que é melhor pensar em abordagens com métodos combinados dos quais a etnografia poderia fazer parte. Mas mesmo a etnografia tradicional obviamente inclui entrevistas, surveys etc.

E2: No livro Theorizing Childhood há quatro abordagens sociológicas diferentes (criança socialmente construída, criança como grupo minoritário, criança tribal e criança como estrutura social). Você mantém isso?

AJ: Eu penso que de maneira geral há ainda essas quatro, mas elas não tinham a intenção de ser descritivas. Elas eram sobre diferentes abordagens para se estudar as crianças e a infância. Embora você possa separá-las e talvez encontrar elementos delas três nos trabalhos de algumas pessoas. Mas há pessoas que estão muito comprometidas com a abordagem dos direitos de grupos minoritários e há pessoas que estão muito comprometidas com a abordagem estrutural, por exemplo. Essas imagens provavelmente ainda funcionam, nós estamos fazendo uma segunda edição desse livro. Veremos quáo longe conseguiremos ir retrabalhando essas imagens.

\section{E2: A criança tribal, por exemplo, você a manteria?}

AJ: A ideia da criança tribal talvez seja menos útil atualmente do que foi antes, porque as pessoas entendem que não é possível pensar nas crianças como um grupo social isolado - suas vidas estâo inseridas na sociedade adulta mais alargada. Nós teremos agora de pensar muito mais em geraçóes. Mas aquele tipo de ação de isolar as crianças para examiná-las, como um grupo social distinto, era importante no início porque nunca havia sido feito antes. Para ver as crianças como atores independentes você precisava colocá-las numa arena própria para conseguir afirmar o que afirmamos, pois do contrário estaríamos apenas fazendo aquela velha discussão sobre socialização. Então ela pode não ser tão útil como foi, mas eu acho que a socialmente construída e a estrutura social e o grupo minoritário ainda são muito importantes.

E2: No livro Handbook of Childhood Studies você menciona, citando Mayall ${ }^{4}$, que ator social e agência sáo conceitos gêmeos. Por quê?? Qual a diferença entre eles? Algumas vezes dizemos que as crianças sáo agentes, mais que somente atores sociais, e isso parece se referir a dois conceitos diferentes.

AJ: Eles são, obviamente, muito relacionados. A agência estritamente é algo mais prático, quer dizer que as crianças estão de fato fazendo alguma coisa acontecer, 
em vez de apenas estarem fazendo coisas. Berry Mayall escreve na perspectiva de criança como grupo minoritário, então ela estaria muito interessada pela noção de que as crianças podem fazer coisas e fazer as coisas acontecerem. Esses são conceitos muito difíceis. Conceitos que precisam ser melhor trabalhados... Parece que há algumas coisas que precisamos fazer nos Estudos da Infância, mais esclarecimentos sobre o que exatamente nós queremos dizer por conceitos como esses, pois os utilizamos de uma forma pouco crítica. Eu certamente os utilizo de forma simplista e acho que poderíamos ganhar desenvolvendo seus usos de maneira mais cuidadosa teoricamente.

\section{E1: Há alguém fazendo isso?}

AJ: Acho que algumas pessoas estão. Há um certo número de pessoas fazendo esse trabalho por aí, mas ainda não chegamos lá. Há alguns artigos nos quais as pessoas começaram a pensar sobre essas questóes mais teoricamente.

\section{E2: $O$ estudo de bebês é parte dos Estudos da Infância? Eles são mais desafia- dores? Por que a maioria dos estudos sáo focados em crianças mais velhas?}

AJ: Eu tenho uma estudante de doutorado [Katherine Monaghan] atualmente estudando bebês e seu argumento é exatamente esse, que os Estudos da Infância não têm incluído bebês. Eu não acho que incluiu. E isso é absolutamente correto e deveria ser incluído. Talvez seja mais desafiador. Nós não podemos entrevistar um bebê facilmente, você precisa observá-los, você precisa trabalhar de outras formas, que é algo que ela está tentando fazer agora. É uma área muito empolgante e que precisa ser incluída nos debates. A questão dela e o que ela quer fazer é olhar para a agência dos bebês.

\section{Estudos da Infância fora do Reino Unido}

\section{E1: Como você vê os Estudos da Infância mundo afora, fora do Reino Unido? Você acha possível falar de Estudos da Infância num contexto náo ocidental?}

AJ: É muito forte na Escandinávia, está crescendo nos Estados Unidos. Acho que algumas das ideias dos Estudos da Infância estão presentes em contextos não ocidentais, mas normalmente estão mais relacionados ao trabalho de ONGs e do pessoal dos direitos das crianças. E como eles estão tomando forma, então é possível que não se queira chamá-los de Estudos da Infância, talvez pudessem ser chamados de direitos das crianças ou desenvolvimento internacional ou algo assim. Há pessoas desenvolvendo Estudos da Infância, por exemplo, na Arábia Saudita. Há uma ex-estudante minha [Hind Khalifa] que está desenvolvendo 
cursos de Estudos da Infância na Arábia Saudita. As coisas estão começando a acontecer, mas não na mesma proporção que na Escandinávia ou no Reino Unido. Mesmo na Europa... em Portugal sim, na Alemanha numa proporção diferente, muito pouco na França, muito pouco na Itália. É muito desigual na Europa. Isso está relacionado em parte ao problema de tradução e todos os textos estão disponíveis somente em inglês. Bem, você sabe disso. Então parte do problema é simplesmente de ordem técnica.

\section{E2: No Brasil a pesquisa baseada nos Estudos da Infância localiza-se princi- palmente nas faculdades de educação. Como você vê esse fenômeno?}

AJ: Isso provavelmente se relaciona com a suposição de que a única coisa interessante sobre as crianças é o que elas se tornarão - e portanto elas se tornando educadas! Mas, é também obviamente importante se, em um nível prático, os professores embarcarem nas ideias dos Estudos da Infância - isso pode ser melhor para as crianças a longo prazo e na sua compreensão mais ampla.

E2: O termo 'diversidade' tem sido utilizado de maneiras diferentes, no Brasil, por exemplo, tem servido para esconder desigualdades. O que diversidade significa no campo dos Estudos da Infância?

AJ: Diversidade se refere à classe, gênero, deficiência e assim por diante, é um termo analítico que significa que em vez de supor a universalidade das crianças e da infância nós nos focamos mais nas diferenças entre as crianças. Nós não supomos que as crianças são todas as mesmas. Então, nesse sentido, pode expor desigualdades. O problema é quando diversidade é utilizada de uma forma política ou simbólica para que as diferenças sejam mascaradas em vez de serem diretamente questionadas como deveriam ser nos Estudos da Infância.

\section{E1: Você teve oportunidade de ler a produçâo brasileira de Estudos da Infân- cia? Quais foram suas impressóes?}

AJ: Já trabalhei com Irene Rizzini e, obviamente, há muita coisa acontecendo no contexto brasileiro e português, o que é muito empolgante. Mas suponho que muitos trabalhos giram em torno da área dos direitos das crianças e eu acho que uma parte disso se deve ao fato de haver mais problemas e questóes em lugares como o Brasil. Há questóes mais importantes em termos de pobreza e assim por diante. Às vezes sinto que de certa forma meu trabalho é mais... Eu suponho que por não estar abordando grandes questóes, de certa forma, é mais limitado, com um foco mais localizado. Talvez no contexto europeu porque não temos os mesmos grandes problemas sociais, nós temos o privilégio de fazer isso porque em lugares como o Brasil há grandes problemas que precisam ser enfrentados nesse momento, [trecho retirado para manter o anonimato]. Os níveis de pobreza, por exemplo. 
Nós temos crianças pobres no Reino Unido e esse número está aumentando, mas elas não são pobres como compreendemos na África ou como compreendemos no Brasil. Provavelmente minha leitura é sobre direitos das crianças em lugares como o Brasil porque essa é a grande questão.

\section{E1: E você poderia nos dizer como foi sua visita ao Brasil? Você esteve lá uma vez, certo?}

AJ: Fui uma vez e estive no CIESPI [Centro Internacional de Estudos e Pesquisas sobre a Infância], o centro coordenado por Irene Rizzini. Meu marido [Adrian L. James] estava lá e nós apresentamos alguns artigos ${ }^{5}$ para um grupo de acadêmicos e também para algumas pessoas que trabalham com jovens nas favelas, o que foi interessante. Tivemos uma conversa sobre o valor dos Estudos da Infância para quem trabalha com jovens, mais focado nas questóes práticas dos Estudos da Infância em termos de teoria transformada em prática, o que é interessante. Fizemos um passeio pelas favelas para que eles nos mostrassem o tipo de trabalho que realizam e foi muito interessante.

\section{E1: Quando foi isso?}

AJ: Três anos atrás.

\section{E1: Náo faz muito tempo.}

AJ: Foi interessante. Eu nunca tinha estado no Brasil, mas foi muito boa aquela conversa sobre a relação entre teoria e prática porque um pesquisador que estava lá, como me lembro, estava justamente preocupado com conceito de agência. Porque é um termo realmente muito difícil para as pessoas trabalharem. Sim, foi uma boa viagem.

\section{Sobre conselhos e novos planos}

\section{E1: Quais sáo suas sugestóes para aqueles que estáo começando suas pesquisas no campo dos Estudos da Infância?}

AJ: Sigam seus interesses teóricos! Nós já temos descrições do dia a dia das crianças suficientes - o que não temos suficiente é a contribuição que os estudos das crianças e da infância podem dar aos grandes problemas e debates - o que acontece com esses problemas e debates quando você os estuda a partir da perspectiva dos Estudos da Infância? Muitos insights e novas ideias interessantes surgem... É isso que é necessário. 


\section{E1: Para finalizar, mais uma pergunta pessoal. Você disse que gostaria de es- crever literatura, certo? Você já escreveu algo?}

AJ: Não, nunca tive tempo. Em minha aposentadoria talvez. Eu normalmente penso que seria capaz de escrever livros infantis, mas não acho que o farei, eu provavelmente escreverei um romance.

\section{E1: Mas você provavelmente escreveu algumas coisas ao longo dos anos...}

AJ: Não, eu nunca fiz isso porque a escrita acadêmica nos consome. Eu nunca tive tempo.

\section{Notas}

1. Uma relaçáo completa de livros e artigos pode ser encontrada no final do texto.

2. JAMES, A. Interdisciplinarity - for better or worse. Children's Geographies, London, v. 8, n. 2, p. 215-6, 2010.

3. JAMES, A. The Name of the Game: nicknames in the child's world. New Society, London, 14th June, 1979.

4. MAYALL, B. Towards a Sociology of Childhood. Buckinghan: Open University Press, 2002.

5. Os textos de Allison James e de Adrian James foram publicados no volume 21 do periódico $O$ Social em Questão, do Departamento de Serviço Social da PUC-Rio, intitulado "Infância: construçôes contemporâneas".

\section{Produção bibliográfica}

\section{Livros}

JAMES, A.; PROUT, A. (1990). Constructing and Reconstructing Childhood. 2 ed. Basingstoke: Falmer Press, 1997.

JAMES, A.; HOCKEY, J. Growing Up and Growing Old: metaphors of ageing in the life course. London: Sage, 1993.

JAMES, A. Childhood Identities: self and social relationships in the experience of the child. Edinburgh: Edinburgh University Press, 1993.

JAMES, A.; HOCKEY, J.; DAWSON, A. After Writing Culture. London: Routledge, 1997.

JAMES, A.; JENKS, C.; PROUT, A. Theorising Childhood. Cambridge: Polity Press, 1998. [Reprinted: 1999; 2001; 2002]. 
CHRISTENSEN, P; JAMES, A. (2000). Research with Children: perspective and practices. London: Falmer Press, 2008 [Investigação com Crianças: Perspectivas e Practicas. Porto: Ediçóes Escola Superior de Educação de Paula Frassinetti, 2005].

JAMES, A.; HOCKEY, J. Social Identities Across the Life Course. London: Macmillan/ Palgrave, 2003.

JAMES, A.; JAMES, A. L. Constructing Childhood: Theory, Law and Social Practice London: Macmillan/Palgrave, 2004.

JAMES, A. et al. The Politics of Childhood. Basingstoke: Palgrave, 2005.

JAMES, A.; HOCKEY, J. Embodying Health Identities. Basingstoke: Palgrave, 2006.

JAMES, A.; JAMES, A. L. European Childhoods: Culture, Politics and Childhood in the European Union. Basingstoke: Palgrave, 2008.

. Key Concepts in Childhood Studies. London: Sage, 2008.

JAMES, A.; KHORHOLT, A. T.; TINGSTAAD, V. Children, Food and Identity in Everyday Life. Basingstoke: Palgrave, 2009.

\section{Artigos}

JAMES, A. Confections, Concoctions and Conceptions. Journal of the Anthropological Society of Oxford, Oxford, v. X, n. 2, p. 83-95, 1979.

1979 .

. The Name of the Game: nicknames in the child's world. New Society, London,

. The good, the bad and the delicious: the role of confectionery in British society.

The Sociological Review, Keele, v. 38, n. 4, p. 666-688, 1990.

. Let's all play nicely: the significance of motifs of separation and transformation in children's play. Ethnografica, Athens, v. IX, p. 161-171, 1994.

. Cuisiner les livres. Identités globales ou locales dans less cultures alimentaires?. Anthropologie et Sociétés, Québec, v.18,. n. 3, p. 39- 57, 1994.

. Learning to be friends: methodological lessons from participant observation among English school children. Childhood, London, v. 3, n. 3, p. 313-330, 1996. [Republicado em 1999 como "Participant observation amongst English school children"].

. Play in Childhood - an anthropological perspective. Child Psychology and Psychiatry Review, Cambridge, v. 3, n. 3, p. 1-6, 1998.

. What can anthropology contribute to early childhood? Educating Young Children, Washington, v. 6, n. 3, p. 6-9, 2000.

. The Standardized Child: Issues of Openness, Objectivity and Agency in promoting child health. Anthropological Journal on European Cultures, London, v. 13, p. 93-110, 2004 .

. Giving voice to children's voices: practices and problems, pitfalls and potentials. American Anthropologist, Arlington, v. 109, n. 2, 2007 
JAMES, A. Conceitos de infância, criança e agência: a construção de hospitais infantis na Inglaterra como estudo de caso. O Social em Questão, Rio de Janeiro, ano XX, n. 21, p. 31-45, 2009.

. Interdisciplinarity - for better or worse. Children's Geographies, London, v. 8, n. 2, p. 215-6, 2010.

To be (come) or not to be (come): understanding children's citizenship. Annals of American Academy of Political and Social Science, Philadelphia, v. 633, n.1, p. 167-179, 2010.

JAMES, A.; CURTIS, P; ELLIS, K. Children's snacking, children's food: food moralities and family life. Children's Geographies, London, v. 8, n. 3, p. 291-302, 2010.

JAMES, A.; CURTIS, P. Family displays and personal lives. Sociology, London, v. 44, n. 6, p. 1163-1180, 2010.

JAMES, A.; CURTIS, P.; STAPLETON, H. Intergenerational relations and the family food environment in families with a child with obesity. Annals of Human Biology, London, v. 38, n. 4, p. 429-437, 2011.

\section{Capítulos de livros}

JAMES, A. Confections, Concoctions and Conceptions. In: WAITES, B.; BENNETT, T.; MARTIN, G. (Eds.). Popular Culture: Past and Present. London: Open University Press, 1982. [Republicado em JENKINS, H. (Ed.). The Children's Culture Reader. New York: New York University Press, 1998].

. Leaning to Belong: the boundaries of adolescence. In: COHEN, A.P. (Ed.). Symbolising Boundaries: Identity and Diversity in British Cultures. Manchester: Manchester University Press, 1986.

. A new paradigm for the sociology of childhood. Provenance, promise and problems. In: JAMES, A.; PROUT, A. (Eds.). Constructing and Reconstructing Childhood. Basingstoke: Falmer Press, 1990.

Re-presenting childhood: time and transition in the study of childhood. In: JAMES, A.; PROUT, A. (Eds.). Constructing and Reconstructing Childhood. Basingstoke: Falmer Press, 1990.

Piggy in the Middle: food symbolism and social relations. In: MARS, G; MARS, V. (Eds.). Food, History and Culture: proceedings of the London Food Seminars. London: London Food Seminar, 1993

. Eating Green(s): organic food and the representation of nature. In: MILTON, K. (Ed.). Environmentalism: the view from anthropology. London: Routledge, 1993.

. Talking of children and youth: language, socialization and culture. In: WULFF, H.; AMIT-TALAI, V. (Eds.). Youth Cultures. London: Routledge, 1995.

. On being a child: the self, the category and the group. In: COHEN, A.P.; RAPPORT, N. (Eds.). Questions of Consciousness. London: Routledge, 1995. 
JAMES, A.; HOCKEY, J. Back to our futures: imaging second childhood. In: FEATHERSTONE, M.; WERNICK, A. (Eds.). Images of Ageing. London: Sage, 1995.

JAMES, A. Cooking the books: global and local identities in food cultures. In: HOWES, D. (Ed.). Cross-Cultural Consumption: global markets and local realities. London: Routledge, 1996.

JAMES, A.; PROUT, A. Strategies and Structures: Towards a New Perspective on children's experiences of family life, In: O'BRIEN, M.; BRANNEN, J. (Eds.). Children in Families: Research and Policy, London: Falmer Press, 1996.

JAMES, A. How British is British Food? In: CAPLAN, P. (Ed.). Food Health and Identity. London: Routledge, 1998.

. Children, health and illness. In: FIELD, D.; TAYLOR, S. (Eds.). Sociological Perspectives on Health and Illness. Oxford: Blackwell, 1998.

JAMES, A. From the child's point of view: issues in the social construction of childhood. In: PANTHER-BRICK, C. (Ed.). Bio-social Perspectives on Childhood. Cambridge: Cambridge University Press, 1998.

. Imaging children 'at home', in the family' and 'at school': movement between the spatial and temporal markers of childhood identity in Britain. In: RAPPORT, N.J.; DAWSON, A. (Eds.). Migrants of Identity. Oxford: Berg, 1998.

. Understanding atypical gender identity in childhood- the contribution of social Anthropology. In: DI CEGLIE, D.; FREEMAN, D. (Eds.). 'A stranger in my body': atypical gender identity and development and mental health. London: Karnac Books, 1998.

JAMES, A.; CHRISTENSEN, P.; HOCKEY, J. You just get on with it: questioning welfare dependency in a rural community. In: EDGAR, I.; RUSSELL, A. (Eds.). Anthropology and Welfare. London: Routledge, 1998.

JAMES, A. Bodies of knowledge: Growing Up and Growing Old. In: POVLSEN, J. et al. (Eds.). Childhood and Old Age: Equals or Opposites? Odense; Odense University Press, 1999.

. Participant observation amongst English schoolchildren. In: WATSON, C.W. (Ed.). Being There: Fieldwork in Anthropology. London: Pluto Press, 1999.

. Parents: a children's perspective. In: BAINHAM, A.; SCLATER, S. D.; RICHARDS, M. (Eds.). What is a parent? A socio-legal analysis. Oxford; Hart Publishing, 1999.

JAMES, A.; CHRISTENSEN, P.; HOCKEY, J. "That's farming, Rosie": power and familial relations in an agricultural community. In: SEYMOUR, J.; BAGGALEY, P. (Eds.). Relating Intimacies: Power and Resistance. London: Macmillan, 1999.

JAMES, A.; HOCKEY, J. The Children's Princess. In: WALTER, T. (Ed.). The Mourning for Diana. Oxford: Berg, 1999.

JAMES, A. Embodied Being(s): Understanding the self and the body in childhood. In: PROUT, A. (Ed.). The Body, Childhood and Society. London: Macmillan, 2000. 
JAMES, A.; CHRISTENSEN, P. Childhood: diversities, conformities and methodological insights. In: CHRISTENSEN, P.; JAMES, A. (Eds.). Research with Children: perspective and practices. London: Falmer, 2000.

JAMES, A.; CHRISTENSEN, P.; JENKS, C. Home and movement: children constructing family time. In: HOLLOWAY, S.; VALENTINE, G. (Eds.). Children's Geographies. London: Routledge, 2000.

JAMES, A. Children and Ethnography. In: DELAMONT, S. et al (Eds.). Handbook of Ethnography. London: Sage, 2001.

. The English Child: towards a cultural politics of childhood identities. In: RAPPORT, N.J. (Ed.). The Best of British. Oxford: Berg, 2001.

JAMES, A.; CHRISTENSEN, P.; HOCKEY, J. Talk, silence and the material world: patterns of indirect communication among agricultural families in Northern England. In: HENDRY, J.; WATSON, W. (Eds.). An Anthropology of Indirect Communication, London: Taylor and Francis, 2001.

JAMES, A.; CHRISTENSEN, P. What are schools for? The temporal experience of learning in Northern England. In: ALLANEN, L.; MAYALL, B. (Eds.). Conceptualising child-adult relations. London: Falmer Press, 2001.

JAMES, A.; CHRISTENSEN, P.; JENKS, C. "All we needed to do was blow the whistle": Children's embodiment of time. In: CUNNINGHAM-BURLEY, S. (Ed.). Exploring the Body. London: Macmillan, 2001.

JAMES, A. An interdisciplinary understanding of childhood. In: PUFALL, P. B.; UNSWORTH R. (Eds.). Rethinking Childhood. New Jersey: Rutgers, 2004.

JAMES, A.; HOCKEY, J. "How do we know that we are aging"? Embodiment, agency and later life. In: TULLE, E. (Ed.). Old Age and Agency. New York: Nova Science Publishers Inc, 2004.

JAMES, A. Life times: children's perspectives on age, agency and memory across the life course. In: QVORTRUP, J. (Ed.). Studies in Modern Childhood: Society, Agency and Culture. London: Palgrave, 2005.

JAMES, A.; JAMES, A. L.; MCNAMEE, S. Family law and the construction of childhood in England and Wales. In: GODDARD, J. et al. (Eds.). The Politics of Childhood. Basingstoke: Palgrave, 2005.

JAMES, A. Day Care or Early Education? Perspectives on the institutional provision for the construction of a 'good' childhood for young children in the UK? In: ROBINSON, G. (Ed.). Contexts of Child Development: Culture, Policy and Intervention. CDU Press, 2008.

JAMES, A.; JAMES, A. L. Changing childhood: reconstructing discourses of 'risk' and 'protection'. In: JAMES, A. L.; JAMES, A. (Eds.). European Childhoods: Culture, Politics and Childhood in the European Union. Basingstoke: Palgrave, 2008. 
JAMES, A.; CURTIS, P; BIRCH, J. Care and control in the construction of children's citizenship. In: WILLIAMS, J.; INVERNIZZI, A. (Eds.). Children and Citizenship. London: Sage, 2008

JAMES, A. Agency. In: QVORTRUP, J.; CORSARO, W.; HONIG, M-S. (Eds.). Handbook of Childhood Studies. London: Sage, 2009.

. "She's got a really good attitude to healthy food ... Nannan's drilled it into her": intergenerational relations in families. In: JACKSON, P. (Ed.). Changing families, Changing Food. Basingstoke: Palgrave, 2009.

. 'Child-centredness' and 'the child': the cultural politics of nursery schooling in England. In: KJORHOLT, A. T.; QVORTRUP, J. (Eds.). The Modern Child and the Flexible Labour Market: early childhood education and care. Basingstoke; Palgrave McMillan, 2011.

\section{Referências bibliográficas complementares}

MAYALL, B. Towards a Sociology of Childhood. Buckinghan: Open University Press, 2002.

Recebido em 23 de janeiro de 2013.

Aprovado em 24 de outubro de 2014.

\section{Errata}

No artigo O Propósito Crítico: Entrevista com Allison James publicada no número 128, volume 35, da Revista Educação \& Sociedade, na página 931, inclusáo da seguinte nota de rodapé:

Agradecemos a Bruna Breda, doutoranda da FEUSP, pela transcrição e tradução da entrevista. 